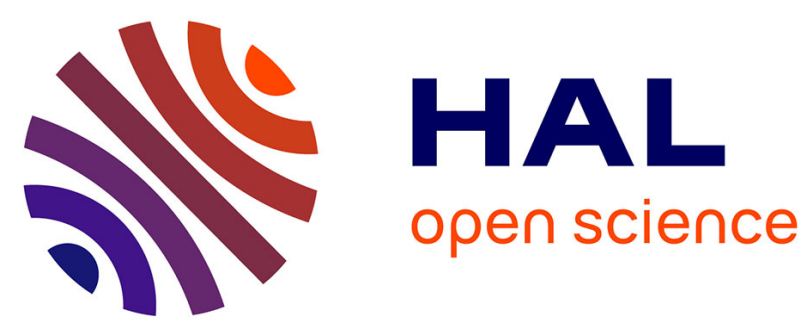

\title{
Light-sensitive dextran-covered PNBA nanoparticles as triggered drug delivery systems: Formulation, characteristics and cytotoxicity
}

Meriem El Founi, Soliman Mehawed Abdellatif Soliman, Régis Vanderesse, Samir Acherar, Emmanuel Guedon, Isabelle Chevalot, Jérôme Babin, Jean-Luc Six

\section{To cite this version:}

Meriem El Founi, Soliman Mehawed Abdellatif Soliman, Régis Vanderesse, Samir Acherar, Emmanuel Guedon, et al.. Light-sensitive dextran-covered PNBA nanoparticles as triggered drug delivery systems: Formulation, characteristics and cytotoxicity. Journal of Colloid and Interface Science, 2018, 514, pp.289 - 298. 10.1016/j.jcis.2017.12.036 . hal-01924074

\section{HAL Id: hal-01924074 \\ https://hal.univ-lorraine.fr/hal-01924074}

Submitted on 17 Mar 2021

HAL is a multi-disciplinary open access archive for the deposit and dissemination of scientific research documents, whether they are published or not. The documents may come from teaching and research institutions in France or abroad, or from public or private research centers.
L'archive ouverte pluridisciplinaire HAL, est destinée au dépôt et à la diffusion de documents scientifiques de niveau recherche, publiés ou non, émanant des établissements d'enseignement et de recherche français ou étrangers, des laboratoires publics ou privés. 


\section{Light-sensitive dextran-covered PNBA nanoparticles}

\section{as triggered drug delivery systems: formulation,}

\section{characteristics and cytotoxicity}

Meriem EL FOUNI ${ }^{a, b}$, Soliman Mehawed Abdellatif SOLIMAN ${ }^{a, b, c}$, Régis VANDERESSE $^{a, b}$,

Samir ACHERAR ${ }^{a, b}$, Emmanuel GUEDON ${ }^{d}$, Isabelle CHEVALOT ${ }^{d}$, Jérôme BABIN ${ }^{a, b}$, Jean-Luc

$$
S I X^{a, b *}
$$

a) Université de Lorraine, Laboratoire de Chimie Physique Macromoléculaire LCPM, UMR 7375, Nancy F-54001, France

b) CNRS, Laboratoire de Chimie Physique Macromoléculaire LCPM, UMR 7375, Nancy F54001, France

c) Chemistry Department, Faculty of Science, Cairo University, 12613 Giza, Egypt.

d) CNRS, Laboratoire Réactions et Génie des Procédés LRGP, UMR 7274, Nancy F-54001, France

Corresponding Author : Jean-Luc SIX (E-mail: jean-luc.six@univ-lorraine.fr)

Submitted to Journal of Colloid and Interface Science 


\section{ABSTRACT}

Hypothesis: For some years, smart nano-objects are one of the main focuses of current research. In the framework of polymeric nanomedicine, o-nitrobenzyl alcohol derivatives lead to lightresponsive polymeric materials. At this day, nanomedicine based on polysaccharide/poly $(o-$ nitrobenzyl acrylate) (PNBA) copolymers have never been reported.

Experiments: For the first time, PNBA core/dextran shell nanoparticles (NPs) were formulated by evaluating two different processes: i) nanoprecipitation of preformed Dextran-g-PNBA glycopolymers, ii) emulsion/evaporation using azido-functionalized PNBA and alkynated dextran, carrying out (or not) an interfacial click chemistry reaction. NPs' characterization, colloidal stability in the presence of salts and an anionic competitive surfactant (SDS) and lightinduced disruption were assessed. Finally, the potential use of these NPs as photo-responsive drug delivery systems was investigated by a preliminary in vitro cytotoxicity study using Caco-2 cells.

Findings: Whatever the process, the photosensitive property and the colloidal stability of NPs in the presence of salts were proved. However, triazole rings between the dextran shell and the PNBA core avoid the dextran shell desorption in the presence of SDS. NPs' biocompatibility towards Caco-2 was proved and $100 \%$ cell viability was still observed after exposure to NPs following by $60 \mathrm{sec}$ UV-irradiation.

KEYWORDS: Drug Delivery System; Polysaccharide; Photo-responsive polymer; Biodegradable; Cancer treatment 


\section{1) INTRODUCTION}

For more than a decade, polymeric nanomedicine that includes micelles, nanoparticles (NPs) or nanocapsules received increasing attention, and many reviews dealing with this subject were published.[1-5] Drug may be loaded into such nano-objects to reduce dosage, minimize sideeffects, protect drug from degradation and thus to enhance its efficiency. Nevertheless, a long period in the bloodstream is often expected (case of stealthy nano-objects). To prevent the adsorption of opsonins (circulating proteins) on the nano-object's surface and its subsequent trapping by the reticuloendothelial system therefore its removing from blood flow,[6-7] polyethylene oxide (PEO, also called polyethylene glycol - PEG) is commonly used to cover the nano-object and to provide it stealthiness. However, although PEO is approved by Food and Drug Administration (FDA)[8] and after close to nearly half a century of clinical uses, it was shown that PEO induces hypersensitivity reaction, complement activation and anti-PEO antibody formation reactions.[8-9] Several neutral hydrophilic polysaccharides were already reported as promising alternatives of PEO due to their inherent biodegradability, immunogenicity, and bioactivity.[10] In fact, some polysaccharides as dextran allow the colloidal stability of such nano-objects,[11-13] prevent interactions with cells and proteins, thus extending the nanoobjects' circulation half-life,[9] and ensuring their stealthiness. After functionalization of such hydrophilic shell (PEG or dextran for instance) by adequate ligands as antibodies, carbohydrates or peptides, nano-objects can target specific cells to be treated. These nano-objects were called drug delivery system (DDS)[14-18] and some of them, based on biodegradable materials, were approved by FDA and are already commercially available.[19]

After encapsulation of drug into DDS, the drug release occurs by DDS degradation or swelling, and/or by diffusion outside the nanocarrier. Commonly, biodegradable hydrophobic 
(co)polyesters as poly(lactic acid) (PLA), poly(glycol acid) (PGA) and their poly(lactide-coglycolide) (PLGA) were used to formulate DDS. In these cases, drug release occurs by diffusion and degradation of the DDS. For some years, scientists took interest to introduce sensitive parts in polymeric materials to reach DDS that are sensitive to internal or external stimuli. Different types of smart or stimuli-responsive DDS are reported as thermosensitive DDS, $\mathrm{pH}$-sensitive DDS, light-sensitive DDS, molecule-responsive DDS, ...[20-24] After DDS formulation and according to adequate stimulation, the loaded drug is released when and where physicians and clinicians want.

Among all the light-responsive polymeric materials described in literature,[25-30] onitrobenzyl alcohol derivatives are today the most studied in polymer science. $o$-Nitrobenzyl ester bonds are known to be cleft by UV or two photons adsorptions, yielding to carboxylic acid functions.[31] Such bonds were already assessed to light-induce the disassembly of block copolymer micelles.[32-36] Very recently, some of us have reported the first controlled polymerization of $o$-nitrobenzyl acrylate (NBA), [37] then the synthesis of amphiphilic grafted photosensitive glycopolymers called Dex-g-PNBA, composed on dextran (Dex) as hydrophilic backbone and poly(o-nitrobenzyl acrylate) (PNBA) as photo-responsive grafts.[38] To the best of our knowledge, the formulation of nano-objects from polysaccharide/PNBA copolymers has never been reported. Indeed, only two papers are dealing with the light-disruption of nanoobjects based on diblock copolymers containing one PNBA block and one poly(2-ethyl-2oxazoline)[39] or polydimethylacrylamide[40] block.

This study aimed to investigate for the first time the formulation of PNBA core / dextran shell NPs that can be used as DDS for anticancer treatments. Two different formulation processes were compared (nanoprecipitation and emulsion/organic solvent evaporation). More precisely, 
within the emulsion/organic solvent evaporation process, an in situ Huisgen-type Copper(I)catalyzed Azide-Alkyne Cycloaddition (CuAAC) click-chemistry was carried out in some experiments. Then, NPs batches were characterized in term of size, zeta potential, dextran amount and colloidal stabilities in the presence of salts and of an anionic competitive surfactant. The photosensitive character of these PNBA-based NPs was evaluated by varying different irradiation parameters. Finally, and because the colorectal cancer is known to be the third most common cancer worldwide[41-43], preliminary study on the in vitro cytotoxicity of these PNBA-based NPs (before and upon UV-irradiation) towards human epithelial colorectal adenocarcinoma (Caco-2) cells was reported.

\section{2) EXPERIMENTAL}

\section{1) Materials}

Amphiphilic alkynated dextran was derived from dextran.[38] The yield of substitution $(\delta)$ of such alkynated dextran was estimated equal to $15 \%$ (15 pending alkynyl groups per 100 glucopyranosic units), and its surface tension property was checked (Figure S1). Azidofunctionalized poly $\left(o\right.$-nitrobenzyl acrylate) $\mathrm{PNBA}_{\mathrm{M}}-\mathrm{N}_{3}$, where $\mathrm{M}$ is the number average molecular weight, was derived from $\mathrm{PNBA}_{\mathrm{M}}-\mathrm{Br}$ obtained via a controlled Single Electron Transfer-Living Radical Polymerization (SET-LRP) of $o$-nitrobenzyl acrylate (NBA).[37] Dexg-PNBA glycopolymers were obtained by carrying out CuAAC in DMSO.[38] For more information, such glycopolymers are called $\operatorname{Dex}(\delta)$-g- $\alpha \mathrm{PNBA}_{\mathrm{M}}$, where $\alpha$ is the number of $\mathrm{PNBA}_{\mathrm{M}}$ grafts per 100 glucopyranosic units. Weight fractions of PNBA $\left(\mathrm{F}_{\mathrm{PNBA}}\right)$ into such Dex- 
g-PNBA are varying from 40 to $85 \%$ as shown in Table 1 . Whatever F $_{\text {PNBA, all Dex-g-PNBA are }}$ insoluble in water, but soluble in DMSO or in $\mathrm{THF} / \mathrm{H}_{2} \mathrm{O}$ mixtures.

Tetrahydrofuran (THF), dichloromethane (DCM), copper bromide (CuBr, 99.9\%), sodium dodecylsulfate (SDS), ethylenediaminetetraacetic acid (EDTA) were purchased from SigmaAldrich and used without further purification.

\section{2) Elaboration of nanoparticles}

\subsection{1) Nanoprecipitation}

$25 \mathrm{mg}$ of Dex-g-PNBA were dissolved in $5 \mathrm{~mL}$ of $\mathrm{THF} / \mathrm{H}_{2} \mathrm{O}$ mixture $(95 / 5, \mathrm{v} / \mathrm{v}$; except in case of Dex(15)-g-3PNBA 3,700 where $75 / 25$, v/v was used) for $24 \mathrm{~h}$, then added drop wise $(0.1 \mathrm{~mL}$ per min) into $10 \mathrm{~mL}$ of distilled water under magnetic stirring. After complete addition, $10 \mathrm{~mL}$ of distilled water were added portion-wise to freeze the NPs dispersion. Finally, THF was removed by centrifugation $\left(15,000 \mathrm{rpm}, 15^{\circ} \mathrm{C}, 30 \mathrm{~min}\right)$. NPs were washed twice by using distilled water, and then were freeze-dried.

\subsection{2) Emulsion/Organic Solvent Evaporation}

$25 \mathrm{mg}$ of either PNBA-Br, $\mathrm{PNBA}_{-\mathrm{N}_{3}}$ or mixtures (from $0 / 1$ to $1 / 0$ ) were dissolved in $1 \mathrm{~mL}$ of DCM. Meanwhile, $50 \mathrm{mg}$ of alkynated dextran were dissolved in $10 \mathrm{~mL}$ of distilled water (DCM-saturated). The organic phase was added under vigorous stirring to the aqueous one, then the mixture was sonicated (pulsed mode, $46 \mathrm{~W}, 2$ min, ice bath) using a Vibracell 75043 model (Bioblock Scientific). After sonication, DCM was evaporated at $37^{\circ} \mathrm{C}$ for $2.5 \mathrm{~h}$ under stirring. Suspension was then centrifuged $\left(10,000 \mathrm{rpm}, 15^{\circ} \mathrm{C}, 60 \mathrm{~min}\right)$ and the collected NPs were 
Table 1. Characterizations of nanoparticles.

\begin{tabular}{|c|c|c|c|c|c|c|}
\hline Run & (a) Method used to produce nanoparticles & (b) Used polymers & $\begin{array}{l}\text { (c) Wt of dextran } \\
\text { (mg/g PNBA) }\end{array}$ & $\begin{array}{l}\text { (d) Z-Average } \\
\text { diameter (nm) }\end{array}$ & (d) PDI & $\begin{array}{l}{ }^{(\mathrm{e})} \Delta_{\mathrm{PZ}} \\
(\mathrm{nm})\end{array}$ \\
\hline 1 & Nanoprecipitation & Dex(15)-g-3PNBA $3,700-F_{\text {PNBA }}=40 \%$ & 916 & $129 \pm 3$ & 0.216 & 10 \\
\hline 2 & Nanoprecipitation & Dex(15)-g-14PNBA ${ }_{3,500}-\mathrm{F}_{\mathrm{PNBA}}=75 \%$ & 310 & $118 \pm 3$ & 0.080 & 5 \\
\hline 3 & Nanoprecipitation & Dex(15)-g-12PNBA ${ }_{9,800}-\mathrm{F}_{\mathrm{PNBA}}=85 \%$ & 153 & $185 \pm 2$ & 0.040 & 3 \\
\hline 4 & Emulsion/Evaporation without CuAAC & $\mathrm{PNBA}_{7,900}-\mathrm{Br} / \mathrm{PNBA}_{8,100}-\mathrm{N}_{3}(1 / 0)$ & 140 & $109 \pm 2$ & 0.144 & ND \\
\hline 5 & Emulsion/Evaporation without CuAAC & $\mathrm{PNBA}_{7,900^{-}} \mathrm{Br} / \mathrm{PNBA}_{8,100^{-}} \mathrm{N}_{3}(0.5 / 0.5)$ & 109 & $132 \pm 2$ & 0.124 & ND \\
\hline 6 & Emulsion/Evaporation without CuAAC & $\mathrm{PNBA}_{7,900}-\mathrm{Br} / \mathrm{PNBA}_{8,100}-\mathrm{N}_{3}(0 / 1)$ & 114 & $140 \pm 0$ & 0.170 & 9 \\
\hline 7 & Emulsion/Evaporation without CuAAC & $\mathrm{PNBA}_{10,300}-\mathrm{Br} / \mathrm{PNBA}_{10,300}-\mathrm{N}_{3}(0 / 1)$ & 109 & $145 \pm 1$ & 0.165 & 8 \\
\hline 8 & Emulsion/Evaporation with CuAAC & $\mathrm{PNBA}_{7,900}-\mathrm{Br} / \mathrm{PNBA}_{8,100}-\mathrm{N}_{3}(0.75 / 0.25)$ & 174 & $131 \pm 3$ & 0.107 & ND \\
\hline 9 & Emulsion/Evaporation with $\mathrm{CuAAC}$ & $\mathrm{PNBA}_{7,900}-\mathrm{Br} / \mathrm{PNBA}_{8,100^{-}}-\mathrm{N}_{3}(0.5 / 0.5)$ & 185 & $125 \pm 1$ & 0.069 & ND \\
\hline 10 & Emulsion/Evaporation with CuAAC & $\mathrm{PNBA}_{7,900}-\mathrm{Br} / \mathrm{PNBA}_{8,100}-\mathrm{N}_{3}(0.25 / 0.75)$ & 174 & $117 \pm 1$ & 0.047 & ND \\
\hline 11 & Emulsion/Evaporation with CuAAC & $\mathrm{PNBA}_{7,900}-\mathrm{Br} / \mathrm{PNBA}_{8,100}-\mathrm{N}_{3}(0 / 1)$ & 185 & $118 \pm 1$ & 0.103 & 10 \\
\hline 12 & Emulsion/Evaporation with CuAAC & $\mathrm{PNBA}_{10,300}-\mathrm{Br} / \mathrm{PNBA}_{10,300}-\mathrm{N}_{3}(0 / 1)$ & 215 & $141 \pm 2$ & 0.181 & 7 \\
\hline
\end{tabular}


(a) Alkynated dextran $(\delta=15 \%)$ was used as surfactant within emulsion/evaporation process

(b) In bracket are given PNBA-Br/ PNBA-N 3 weight ratios used. $\mathrm{F}_{\mathrm{PNBA}}$ is the weight fraction of PNBA in the glycopolymer, calculated from ${ }^{1} \mathrm{H}$ NMR spectrum $\left(\mathrm{DMSO}-d_{6}\right)$ using

. $\mathrm{A}_{\mathrm{CH} 2}$ and $\mathrm{A}_{\mathrm{Ha}}$ are the areas under

characteristic peaks of $\mathrm{OCH}_{2}$ protons of each NBA monomer unit (molecular weight $=207 \mathrm{~g} / \mathrm{mol}$ ) and anomeric proton of each glucopyranosic unit, respectively. $176.1 \mathrm{~g} / \mathrm{mol}$ is the average molecular weight of alkynated glucopyranosic unit $(\delta=15 \%)$.[38]

(c) Weight fraction of dextran per gram of PNBA in NPs. See experimental part.

(d) Estimated by Dynamic Light Scattering (DLS). See experimental part.

(e) Dextran layer thickness, obtained from zeta potential measurements. See experimental part. ND means not determined. 
resuspended in water, centrifuged again in order to remove the non-adsorbed alkynated dextran, and finally freeze-dried.

In some experiments an in situ CuAAC was carried out by adding $5 \mathrm{mg}$ of $\mathrm{CuBr}$ to the first emulsion under $\mathrm{N}_{2}$ flow and prior to the sonication step. To remove residual copper, EDTA (5 eq per $\mathrm{CuBr}$ ) was added to the final washed NPs suspension, which was left under stirring for $24 \mathrm{~h}$ at room temperature, then centrifuged $\left(10,000 \mathrm{rpm}, 15^{\circ} \mathrm{C}, 30-60 \mathrm{~min}\right)$, and finally washed twice with deionized water.

In the case of uncoated NPs, the initial aqueous phase was composed of $3 \mathrm{~g} / \mathrm{L}$ of SDS instead of alkynated dextran.

\section{3) Characterization of nanoparticles}

The Dynamic Light Scattering (DLS) at low concentration was evaluated using a Malvern High Performance Particle Sizer (HPPS) instrument. The average scattering intensity during the measurement is called Mean Count Rate (MCR) and the analysis of the intensity fluctuations allows to estimate the NPs' size and the polydispersity index (PDI). Although this apparatus is able to measure relatively concentrated samples, $200 \mu \mathrm{L}$ of NPs suspension were diluted in $2 \mathrm{~mL}$ of $\mathrm{NaCl}$ aqueous solution $\left(10^{-3} \mathrm{M}\right)$. In case of irradiated NPs (see below), $200 \mu \mathrm{L}$ of irradiated suspension were mixed with $2 \mathrm{~mL}$ of Phosphate Buffer Saline (PBS, $\mathrm{KH}_{2} \mathrm{PO}_{4} / \mathrm{Na}_{2} \mathrm{HPO}_{4}, \mathrm{pH}=$ 7) $/ \mathrm{H}_{2} \mathrm{O}$ mixture $\left.(50 / 50, \mathrm{v} / \mathrm{v})\right)$. The final NPs dispersion concentration was equal to $0.11 \mathrm{mg} / \mathrm{mL}$. The mean diameter $\mathrm{Dz}(\mathrm{nm})$ is the so-called Z-average from cumulated analysis, i.e. an intensity-average diameter, and was measured three times with deviation remaining below $5 \mathrm{~nm}$. 
After freeze-drying, NPs were dissolved in DMSO- $d_{6}$ and the weight of dextran $(\mathrm{mg})$ per gram of PNBA was estimated from ${ }^{1} \mathrm{H}$ NMR spectrum (Figure 1), according to equation (1). ${ }^{1} \mathrm{H}$ NMR spectra were recorded on a Bruker Avance 300 apparatus $\left(300.13 \mathrm{MHz}, 25^{\circ} \mathrm{C}\right)$ in DMSO- $d_{6}$.

$$
\text { Wt of dextran }(\mathrm{mg})=1000 \times \frac{A_{\mathrm{Ha}} \times 162}{\left(A_{\mathrm{CHz}} / 2\right) \times 207}
$$

where $\mathrm{A}_{\mathrm{Ha}}(4.7 \mathrm{ppm})$ and $\mathrm{A}_{\mathrm{CH} 2}(5.25 \mathrm{ppm})$ are the areas of anomeric protons and PNBA benzylic methylene ones, respectively. 162 and 207 are the molecular weights $(\mathrm{g} / \mathrm{mol})$ of glucosidic and NBA monomer units, respectively.

\section{4) Zeta potential and adsorption layer thickness}

The electrophoretic mobility was measured in $\mathrm{NaCl}$ solutions of variable concentration $\left(10^{-5}\right.$ to $\left.10^{-2} \mathrm{M}\right)$ using a Malvern Zetasizer Nano-Z instrument. Calculations of zeta potential $(\zeta)$ were done from the electrophoretic mobility using the modified Booth equation.[44] As already reported,[12,45] this equation allows the calculation of $\zeta$ values for any $\mathrm{k}_{\mathrm{H}}$ and a values, where $\mathrm{k}_{\mathrm{H}}{ }^{-1}$ is the Debye length related to the ionic strength, and a the radius of NPs. On the opposite, the classical Smoluchowski and Huckel equation are applicable only under two limiting cases, i.e., $\left(\mathrm{k}_{\mathrm{H}} \times \mathrm{a}\right)>100$ and $\left(\mathrm{k}_{\mathrm{H}} \times \mathrm{a}\right)<0.1$, respectively. $\zeta$ values were used to estimate the thickness

of the adsorption layer $\left(\Delta_{\mathrm{PZ}}\right)$ by using the Eversole and Boardman equation (2).[46]

$\ln \left[\tanh \left(\frac{\mathrm{z}_{\mathrm{e} \zeta}}{4 \mathrm{k}_{\mathrm{B}} \mathrm{T}}\right)\right]=\ln \left[\tanh \left(\frac{\mathrm{z}_{\mathrm{e}} \zeta_{\mathrm{o}}}{4 \mathrm{k}_{\mathrm{B}} \mathrm{T}}\right)\right]-\mathrm{k}_{\mathrm{H}} \times \Delta_{\mathrm{pZ}}$

where $\mathrm{Z}=1$ (charge of $\mathrm{Na}^{+}, \mathrm{Cl}^{-}$ions), $\zeta_{0}$ is the surface potential of the $\mathrm{NP}$, e is the elementary charge of electron, $\mathrm{k}_{\mathrm{B}}$ is the Boltzmann constant, $\mathrm{T}$ is the absolute temperature and $\Delta_{\mathrm{PZ}}$ is the 


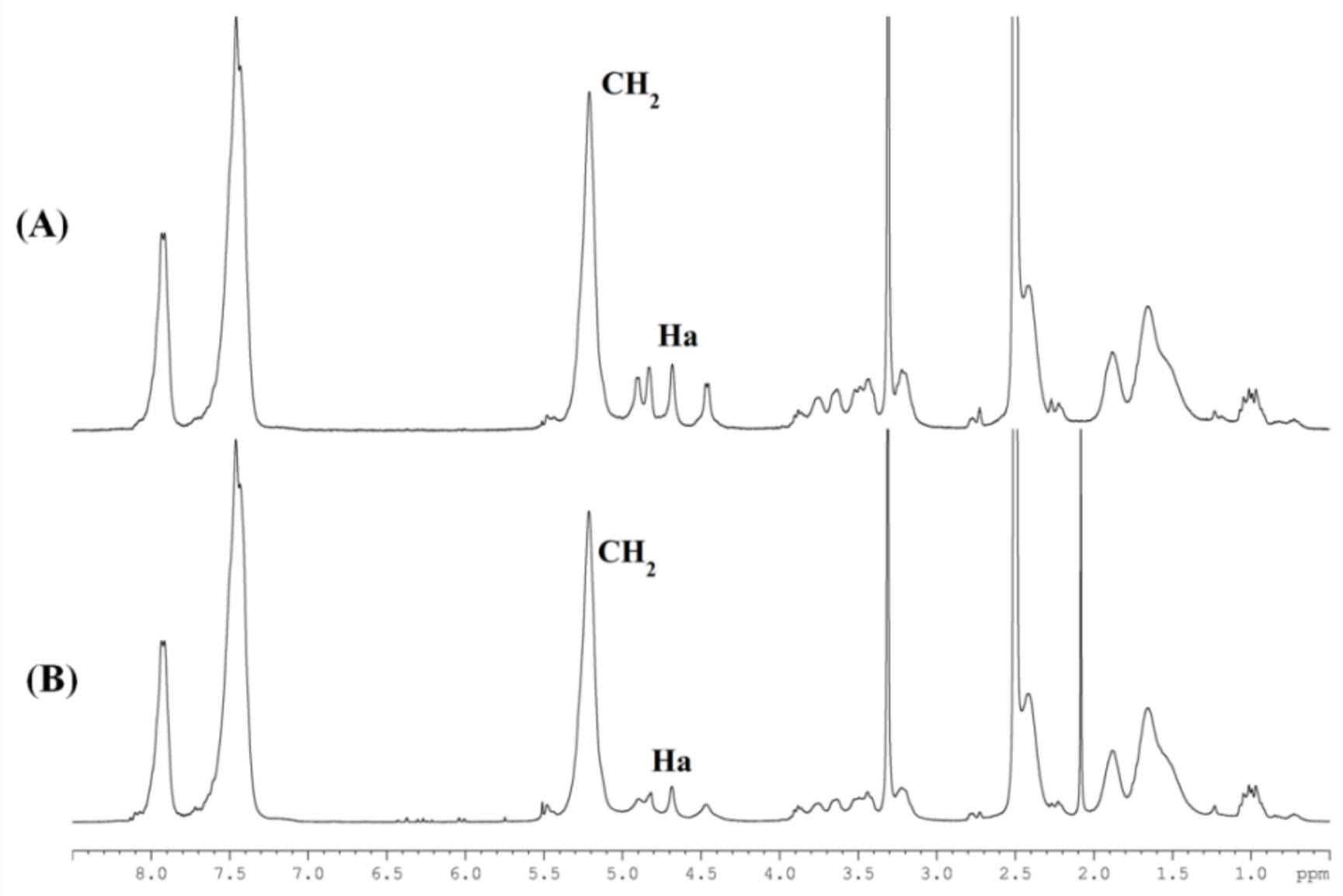

Figure 1. ${ }^{1} \mathrm{H}$ NMR spectra (DMSO- $d_{6}$ ) of NPs prepared by emulsion/organic solvent evaporation with (A) and without (B) in situ interfacial CuAAC. 
distance of the shear plane from the surface of the NP, corresponding approximately to the adsorbed layer thickness. Thus, the plot of $\ln \left[\tanh \left(\frac{\mathrm{z}_{e} \zeta}{4 \mathrm{k}_{\mathrm{B}} \mathrm{T}}\right)\right]$ versus $\mathrm{k}_{\mathrm{H}}$ gave a straight line with $\Delta_{\mathrm{PZ}}$ as slope (determined at lower $\mathrm{k}_{\mathrm{H}}$ values), as already described.[11,12,45]

\section{5) Colloidal stability of nanoparticles}

The colloidal stability of NPs dispersions in the presence of $\mathrm{NaCl}$ was assessed by turbidimetry using UVikon XL Spectrophotometer (Bio-Tek Instruments). Typically, $0.5 \mathrm{~mL}$ of NPs dispersion $(0.11 \mathrm{mg} / \mathrm{mL})$ was added to $3 \mathrm{~mL}$ of $\mathrm{NaCl}$ solutions (concentrations ranging from $10^{-4}$ to $5 \mathrm{M}$ ). The samples were allowed to stand in the dark before the analysis. Their optical density (OD) was measured over the range $450-650 \mathrm{~nm}$ at $50 \mathrm{~nm}$ intervals. For each $\mathrm{NaCl}$ concentration, the curve $\log (\mathrm{OD})$ as a function of $\log (\lambda)$ was plotted, where $\lambda$ is the wavelength. The slope $\mathrm{d}(\log \mathrm{OD}) / \mathrm{d} \lambda$, called $n$, was calculated and taken as an indication of NPs size.[11,12,45] Indeed, the occurrence of flocculation upon increasing ionic strength was evidenced by a sharp decrease in $n$ values.

The colloidal stability of NPs suspension toward SDS was carried out after adding SDS aqueous solution ( $1 \%$ weight) to the suspension. The sample was allowed to stand for $24 \mathrm{~h}$ under stirring, in the dark. NPs were then centrifuged, washed twice with deionized water, freeze-dried and dissolved in DMSO- $d_{6}$ to quantify the amount of residual dextran on the surface of NPs.[12,45] The percentage of desorbed dextran was calculated using equation (3), where $\mathrm{Wt}_{\text {inital }}$ and $\mathrm{Wt}_{\text {final }}$ correspond to the weight of dextran (mg) per gram of PNBA before and after treatment by SDS, respectively. 
Desorbed dextran $(\%)=100 \times\left(1-\frac{W t_{\text {tinitial }}}{W t_{\text {final }}}\right)$

\section{6) Light irradiation of PNBA-based nanoparticles}

To study the light-induced disruption of PNBA-based NPs, $3 \mathrm{~mL}$ of NPs suspension $(0.11$ $\mathrm{mg} / \mathrm{mL})$ in PBS $(\mathrm{pH}=7)$ were irradiated in $1 \mathrm{~cm} \times 1 \mathrm{~cm}$ quartz cuvette with a OmniCure®S1000 UV spot cure lamp in the power range of $54-1150 \mathrm{~mW} / \mathrm{cm}^{2}$. A light guide of $8 \mathrm{~mm}$ diameter equipped with a 320-500 nm filter was used. After irradiation, the Mean Count Rate value (MCR) was measured on the one hand. On the other hand, NPs were washed by DCM using separatory funnel to dissolve and extract $o$-nitrosobenzaldehyde (Figure S2). Finally, NPs suspension was freeze dried for $48 \mathrm{~h}$ prior to NMR characterizations.

\section{7) In vitro cytotoxicity and cells viability}

Caco-2 cells were cultivated in an appropriate culture medium (Dulbecco modified eagle's medium - DMEM) with high glucose concentration (4.5 g/L), 4 mM L-glutamine, supplemented with $10 \%$ foetal bovine serum, and $1 \%$ antibiotic antimycotic solution (Sigma). The cells were usually split when reaching 80\% confluence (5-7 days). They were first rinsed with Dulbecco's phosphate-buffered saline without calcium (D-PBS) (Sigma), then trypsinized with a solution containing $0.25 \%$ trypsin and $1 \mathrm{mM}$ EDTA (GIBCO).

Caco-2 cells were seeded into 96-well microplates at $1.10^{4}$ cells/well in $200 \mu \mathrm{L}$ of culture medium. After $24 \mathrm{~h}$, two sets of experiments were performed: i) cells were irradiated and incubated for another $24 \mathrm{~h}$ or $48 \mathrm{~h}$ at $37^{\circ} \mathrm{C}$, under $5 \% \mathrm{CO}_{2}$ atmosphere, ii) cells were incubated with various NPs dispersion concentrations $(<230 \mu \mathrm{g} / \mathrm{mL})$, then irradiated (or not) and incubated for another $24 \mathrm{~h}$ or $48 \mathrm{~h}$ at $37 \mathrm{C}$, under $5 \% \mathrm{CO}_{2}$ atmosphere. In some experiments, the culture medium was changed $4 \mathrm{~h}$ after the irradiation, then cells were incubated for another $24 \mathrm{~h}$ or $48 \mathrm{~h}$ 
at $37{ }^{\circ} \mathrm{C}$, under $5 \% \mathrm{CO}_{2}$ atmosphere. Also, cells without irradiation and without NPs addition were cultivated as controls.

After incubation, culture medium was removed and $200 \mu \mathrm{L}$ of fresh medium were then added. The cell viability was determined using MTT assay, using mitochondrial succinate dehydrogenase activity of viable cells by the reduction of the yellow coloured tetrazolium salt, 3(4,5-dimethylthiazol-2-yl)-2,5-diphenyl tetrazolium bromide, into a blue coloured formazan product.[47] More precisely, $50 \mu \mathrm{L}$ of MTT solution ( $2 \mathrm{~g} / \mathrm{L})$ were added in each well. After incubation for $3 \mathrm{~h}$ at $37^{\circ} \mathrm{C}$, formazan crystals were observed, dissolved with $150 \mu \mathrm{L}$ of isopropyl alcohol, then spectrophotometrically quantified at $550 \mathrm{~nm}$ using a multi-well plate reader. OD value was subjected to the percentage of cell viability using equation (4):

Percentage of cell viability (\%) $=\frac{\text { OD value of experimental samples }}{\text { OD value of experimental controls }} \times 100$

All these cytotoxicity experiments were performed in triplicate. Error bars (see below) represent standard deviation (SD) of the mean value for two independent experiments. One-way analysis of variance was performed by ANOVA procedure. Significant differences between means were determined by Duncan's Multiple Range tests. Differences at $\mathrm{p}>0.05$ were considered significant.

\section{3) RESULTS AND DISCUSSION}

\section{1) Nanoparticles by nanoprecipitation}

None of the Dex-g-PNBA glycopolymers were soluble in acetone $/ \mathrm{H}_{2} \mathrm{O}$ mixtures commonly used in nanoprecipitation method.[12] Fortunately, THF/ $\mathrm{H}_{2} \mathrm{O}$ mixture can be used to dissolve 
Dex-g-PNBA with $\mathrm{F}_{\mathrm{PNBA}}$ higher than or equal to $40 \%$ (Table 1) to formulate PNBA-based NPs by nanoprecipitation. In this process, another surfactant was not required in the water phase according to the amphiphilic properties of such Dex-g-PNBA. As shown in Table 1, only one population of NPs was obtained with low PDI, whatever the glycopolymer used. The Z-average diameter of NPs based on Dex(15)-g-12PNBA 9,800 (Run 3, Table 1) was larger than that of the two other batches (Runs 1-2, Table 1) due to its high weight fraction of PNBA. For each NPs batch, electrophoretic mobility was measured in different $\mathrm{NaCl}$ concentrations and compared to uncoated PNBA NPs (Figure 2). In the case of low $\mathrm{NaCl}$ concentration $\left(10^{-5} \mathrm{M}\right)$, we estimated zeta potential values $(\zeta)$ equal to -31.7 and $-42.6 \mathrm{mV}$ for NPs based on $\operatorname{Dex}(15)$-g-14PNBA 3,500 and Dex(15)-g-12PNBA9,800, respectively (Runs 2-3, Table 1, Figure 2), that was higher than the

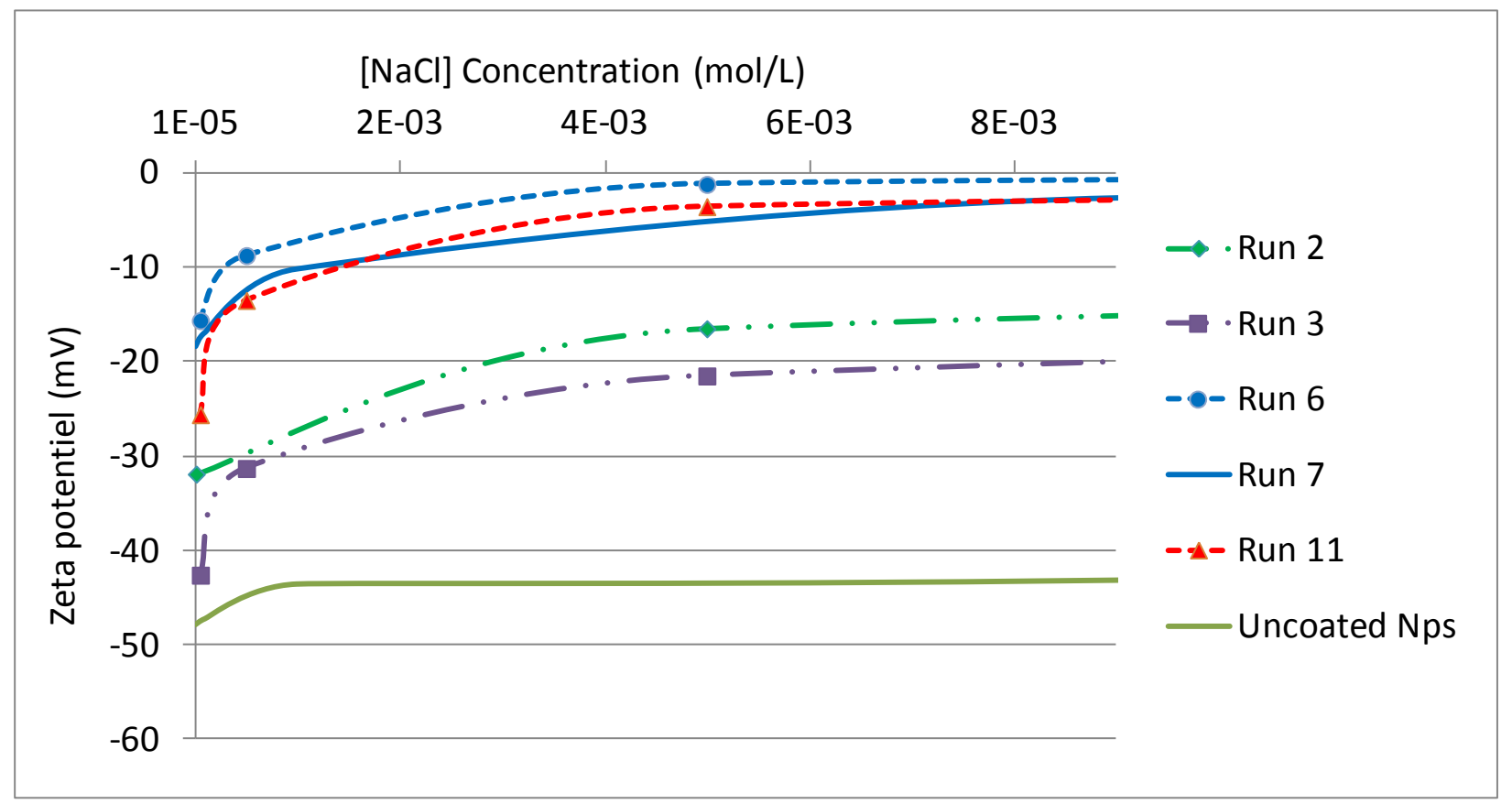

Figure 2. Evolution of zeta potential for NPs made by nanoprecipitation of Dex-g-PNBA (Runs 2 and 3, Table 1) or by emulsion/evaporation with (or not) in situ CuAAC (Runs 6, 7 and 11, Table 1) against concentration of $\mathrm{NaCl}$. 
value estimated in case of uncoated NPs. These values indicate the presence of negative charges at the NPs surface according to the ester groups of PNBA chains that may lead to ionized carboxylic groups on the surface, as currently reported for polylactide NPs.[12] Nevertheless, these charges were screened by increasing the ionic strength of $\mathrm{NaCl}$ concentration evidencing the presence of a neutral dextran outer layer covering NPs (not in case of uncoated NPs, Figure 2). This effect was already reported in case of PLA core / dextran shell NPs.[12]

Using Eversole and Boardman equation (2), the outer dextran shell thickness $\left(\Delta_{\mathrm{PZ}}\right)$ was estimated from $\zeta$ measurements. Increasing $\mathrm{F}_{\mathrm{PNBA}}$ in glycopolymer led to decrease both the weight fraction of dextran per gram of PNBA and the $\Delta_{\mathrm{PZ}}$. Indeed, the increase of the hydrophobicity of such glycopolymers (increase of $F_{\mathrm{PNBA}}$ ) leads to a lower expansion of the outer dextran layer shell and decrease of $\Delta_{\mathrm{PZ}}$ (Table 1).

\section{2) Nanoparticles by Emulsion/Organic Solvent Evaporation}

Emulsion/organic solvent evaporation method is another technique commonly used to formulate NPs dispersion with narrow polydispersity.[12,13,48] In the present study, the organic phase was loaded with either $\mathrm{PNBA}_{\mathrm{M}}-\mathrm{N}_{3}, \mathrm{PNBA}_{\mathrm{M}}-\mathrm{Br}$ or mixtures (from 0/1 to $1 / 0$ ), while the aqueous one was containing amphiphilic alkynated dextran. Using such emulsion/evaporation process provides a colloidal system based on a hydrophobic PNBA core surrounded by a physically adsorbed alkynated dextran shell. When using $\mathrm{PNBA}_{7,900}-\mathrm{Br}$ only (run 4, Table 1), a Z-average diameter of NPs equal to $109 \mathrm{~nm}$ and the amount of dextran per gram of PNBA equal to $140 \mathrm{mg}$ were estimated. When using $\mathrm{PNBA}_{7,900}-\mathrm{Br} / \mathrm{PNBA}_{8,100}-\mathrm{N}_{3}(0.5 / 0.5)$ mixture or $\mathrm{PNBA}^{-\mathrm{N}_{3}}$ only $\left(\mathrm{PNBA}_{8,100}-\mathrm{N}_{3}\right.$ or $\mathrm{PNBA}_{10,300}-\mathrm{N}_{3}$ ), both similar amounts of dextran per gram of PNBA (around $110 \mathrm{mg})$ and Z-average diameters of NPs (130-145 nm) were measured, whatever the PNBA molecular weight (runs 5-7, Table 1). A lower weight fraction of dextran (mg) per gram of 
PNBA was estimated, that may be due to the lower hydrophobicity of azide end functions compared to bromide ones.

In some other experiments, "clicked" NPs were prepared by emulsion/evaporation process carrying out an in situ interfacial CuAAC click reaction.[12,45] For instance, when using $\mathrm{PNBA}_{7,900}-\mathrm{Br} / \mathrm{PNBA}_{8,100}-\mathrm{N}_{3}$ mixtures, an in situ CuAAC occurred at the liquid/liquid interface by adding $\mathrm{CuBr}$ into the medium, prior to sonication step. Carrying out such in situ click chemistry between azide and alkyne functions during the sonication step $[12,45]$ leads to produce amphiphilic Dex(15)-g- $\alpha \mathrm{PNBA}_{8,100}$ glycopolymers at the liquid/liquid interface, allowing to covalently link the dextran shell on the PNBA core via triazole rings. Such Dex(15)-g$\alpha \mathrm{PNBA}_{8,100}$ in situ produced at this interface are more hydrophobic than alkynated dextran, leading to increase the amount of dextran (> $170 \mathrm{mg} / \mathrm{g}$ PNBA) while similar Z-average diameters of NPs (around $120 \mathrm{~nm}$ ) were estimated (runs 8-11, Table 1). Increasing the molecular weight of PNBA-N $\mathrm{N}_{3}$ (run 12, Table 1) increases both the Z-average diameter and the weight fraction of dextran (mg) per gram of PNBA according to a higher hydrophobic Dex-g-PNBA in situ produced. Such in situ CuAAC can also be carried out in absence of $\mathrm{N}_{2}$ flow without affecting the Z-average diameter of NPs, as shown in Figure S3.

For each NPs batch formulated by emulsion/organic solvent evaporation, with and without in situ $\mathrm{CuAAC}$, electrophoretic mobility was measured in different $\mathrm{NaCl}$ concentrations, as already done in the case of nanoprecipitation process (Figure 2). In the case of low $\mathrm{NaCl}$ concentration $\left(10^{-5} \mathrm{M}\right)$, we estimated $\zeta$ equal to $-15.6,-18.5$ and $-25.6 \mathrm{mV}$ for NPs made by emulsion/evaporation process with (or not) in situ CuAAC, respectively (Runs 6, 7 and 11, Table 1, Figure 2). Such charges were screened by increasing the ionic strength of $\mathrm{NaCl}$ concentration, evidencing the presence of a neutral dextran outer layer covering PNBA core NPs. $\Delta_{\mathrm{PZ}}$ estimated 
by equation (2) were similar (from 7 to $10 \mathrm{~nm}$ ) whatever the occurrence of the in situ CuAAC, which means that carrying out (or not) such a reaction does not significantly influence the $\Delta_{\mathrm{PZ}}$. In situ $\mathrm{CuAAC}$ leads to the formation of $\operatorname{Dex}(15)-\mathrm{g}-\alpha \mathrm{PNBA}_{8,100}$ glycopolymers at the liquid/liquid interface (run 11, Table 1). By comparison with data of run 3 (NPs produced by nanoprecipitation of $\left.\operatorname{Dex}(15)-\mathrm{g}-12 \mathrm{PNBA}_{9,800}\right)$, we can observe a thicker dextran shell in the case of run 11. This result could be explained by a faster formation of NPs by nanoprecipitation than using emulsion/evaporation process, even with CuAAC, in agreement with work done by Couvreur et al. [50]

\section{3) Nanoparticles dispersion stability}

Firstly, the colloidal stability of NPs dispersions in $\mathrm{NaCl}$ medium was assessed during at least 15 days in the dark by turbidimetry as a function of different ionic strengths. As already reported for other dextran-covered NPs[11,12,45], all the PNBA-based NPs dispersions were proved to be stable over the whole $\mathrm{NaCl}$ concentrations (from $10^{-4}$ to $5 \mathrm{M}$ ), whatever the formulation process used (Figure S4). Same experiments were carried out under exposure to natural light and we observed a $5 \mathrm{~nm}$ decrease in NPs diameter. According to these results, injection of such NPs in the bloodstream may be considered as ionic strength of blood equal to 0.15 . Nevertheless, circulating proteins may desorb the dextran shell of NPs.

To evaluate the stability of the dextran outer shell towards circulating proteins, NPs suspension was stirred over $24 \mathrm{~h}$ in presence of an anionic drastic competitive surfactant (SDS) that will mimic the proteins action. Desorption of adsorbed polymers by SDS has already been reported in the literature to evaluate the strength of amphiphilic copolymers adsorption.[51-53] In recent papers, we proved that one physically absorbed dextran outer layer onto PLA-core NPs[12] or onto PLA shell / oily core nanocapsules[45] cannot ensure colloidal stability against such SDS. 
On the one hand, NPs were formulated by emulsion/evaporation process carrying out an in situ CuAAC. As above written, triazole rings were produced to covalently link dextran shell onto the PNBA core. On an opposite way, without interfacial CuAAC, alkynated dextran was only physically adsorbed at the NPs surface. Figure 3(A,B) shows ${ }^{1} \mathrm{H}$ NMR spectra of such "clicked" NPs before and after contact with SDS. As one can see, dextran characteristic peaks were still present in the spectrum after SDS contact, testifying the presence of triazole rings are preventing the desorption of dextran shell. More precisely, only $4 \%$ (15\%) of the dextran shell were desorbed by the competitive SDS when the in situ CuAAC was occurred under $\mathrm{N}_{2}$ flow (without $\mathrm{N}_{2}$ flow). On the other hand, when NPs were formulated without in situ CuAAC, 85\% of the dextran shell were desorbed after SDS contact. Finally, in the case of NPs produced by nanoprecipitation, no desorption of the dextran shell was observed according to the triazole links between dextran and PNBA parts in glycopolymers.

\section{4) Light irradiation of PNBA-based nanoparticles}

Photosensitive properties of both PNBA[37] and dextran-g-PNBA glycopolymers[38] were already reported by some of us. We also proved that dextran part in such glycopolymers does not prevent, but delays the PNBA photolysis. Consequently, Dex-g-PNBA glycopolymers give dextran-g-poly(acrylic acid) (Dex-g-PAA) ones at total photolysis conversion (Figure S2). Nevertheless, if photolysis is not quantitative, dextran-g-P(NBA-co-AA) are produced.[38]

To investigate the light irradiation effect on PNBA-based NPs, we arbitrarily selected NPs based on either Dex(15)-g-14PNBA 3,500 (run 2, Table 1) or produced by emulsion/evaporation process with (or not) in situ CuAAC (runs 5 and 9, Table 1). Firstly, we monitored the $\mathrm{pH}$ of the NPs dispersion during UV irradiation. As shown in Table 2, $\mathrm{pH}$ of dispersion decreased, confirming the formation of free carboxylic groups according to Figure S2. Similar results were observed for 


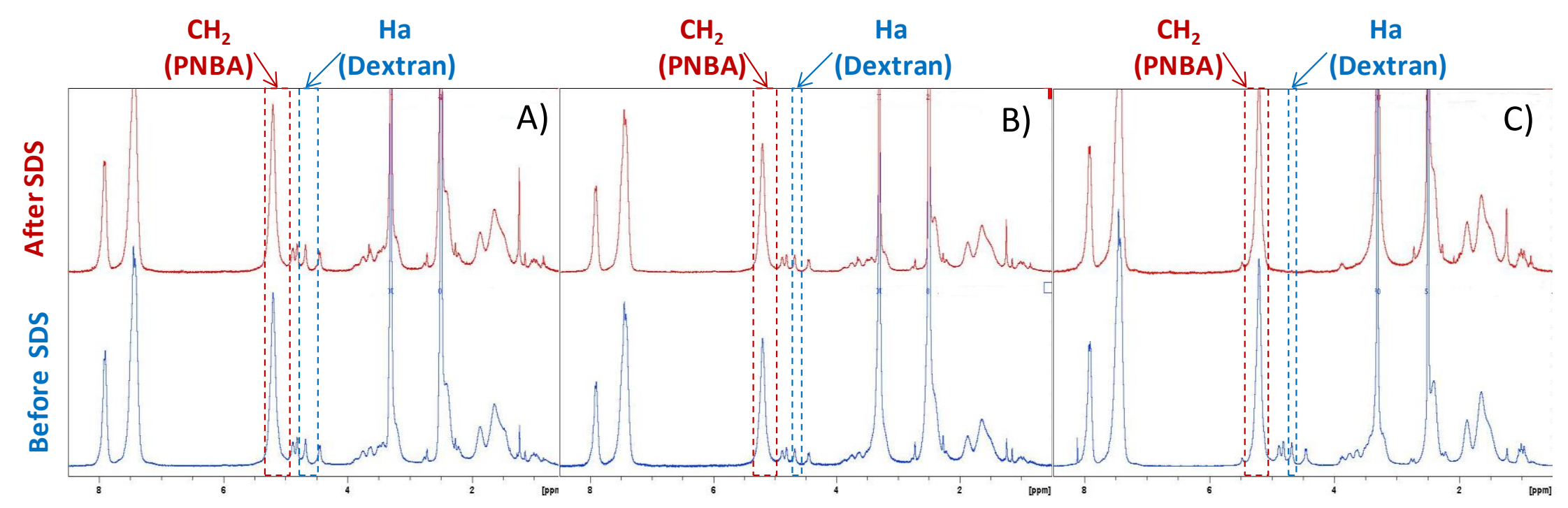

Figure 3. ${ }^{1} \mathrm{H}$ NMR spectra $\left(\mathrm{DMSO}-d_{6}\right)$ of NPs produced with $(\mathrm{A}, \mathrm{B})$ or without $(\mathrm{C})$ in situ CuAAC. Click chemistry was carried out under (A) or without (B) $\mathrm{N}_{2}$ flow. Spectra are given before and after SDS contact. 
Table 2. Photolysis conversion of $3 \mathrm{~mL}$ dispersion of NPs based on Dex(15)-g-14PNBA 3,500 $(0.11 \mathrm{mg} / \mathrm{mL})$ versus $\mathrm{UV}$ irradiation.

(a) UV-lamp power $=1150 \mathrm{~mW} / \mathrm{cm}^{2}$

\begin{tabular}{|c|c|c|c|}
\hline Duration of irradiation $^{(\mathrm{a})}$ & $\mathrm{A}_{\mathrm{CH} 2} / \mathrm{A}_{\mathrm{Ha}}{ }^{(\mathrm{b})}$ & $\%$ Photolysis ${ }^{(\mathrm{c})}$ & $\mathrm{pH}$ of dispersion \\
\hline Without irradiation & 5.05 & 0 & 7.18 \\
\hline $2 \mathrm{~min}$ & 3.38 & 33 & 6.40 \\
\hline $5 \mathrm{~min}$ & 0.51 & 90 & 5.30 \\
\hline $10 \mathrm{~min}$ & - & - & 3.81 \\
\hline
\end{tabular}

(b) $\mathrm{A}_{\mathrm{CH} 2}$ and $\mathrm{A}_{\mathrm{Ha}}$ are the areas under characteristic peaks of $\mathrm{CH}_{2}$ protons of each NBA monomer unit and anomeric proton $\left(\mathrm{H}_{\mathrm{a}}\right)$ of each glucopyranosic unit, respectively.

(c) Yield of photolysis (\%) $=100 \times\left[1-\left(\left(\frac{A_{C H z} / 2}{A_{H a}}\right)_{t} /\left(\frac{A_{C H z} / 2}{A_{H a}}\right)_{t=0}\right)\right]$

both formulation processes. Consequently to simplify the reading, we will show only results for NPs made by nanoprecipitation.

${ }^{1} \mathrm{H}$ NMR spectra (DMSO- $d_{6}$ ) of irradiated NPs show a decrease of $\mathrm{A}_{\mathrm{CH} 2} / \mathrm{A}_{\mathrm{Ha}}$ ratio depending on the irradiation duration, where $\mathrm{A}_{\mathrm{CH} 2}$ and $\mathrm{A}_{\mathrm{Ha}}$ are the areas under characteristic peaks of $\mathrm{CH}_{2}$ protons of each NBA monomer unit and anomeric proton $\left(\mathrm{H}_{\mathrm{a}}\right)$ of each glucopyranosic unit, respectively. From this $\mathrm{A}_{\mathrm{CH} 2} / \mathrm{A}_{\mathrm{Ha}}$ ratio, the yield of photolysis can be estimated (Table 2). As shown, 90\% photolysis was reached after 5 min UV-irradiation (power $1150 \mathrm{~mW} / \mathrm{cm}^{2}$ ). These results are in agreement with our previous results wherein no further evolution of the absorbance at $325 \mathrm{~nm}$ (characteristic of $o$-nitrosobenzaldehyde by-product) was observed after $5 \mathrm{~min}$ irradiation of Dex-g-PNBA under this power irradiation.[38] After 10 min UV irradiation, no 
peak was observed on the ${ }^{1} \mathrm{H}$ NMR spectrum and we think that PNBA grafts were totally hydrolyzed in PAA grafts at this time, leading to Dex-g-PAA not soluble in DMSO- $d_{6}$ or $\mathrm{D}_{2} \mathrm{O}$. FT-IR charts of non-irradiated and irradiated NPs based on Dex(15)-g-14PNBA 3,500 are shown in Figure 4A. In case of non-irradiated NPs, one can see stretching bands at 1345 and $1579 \mathrm{~cm}^{-1}$ characteristic of $\mathrm{NO}_{2}$ groups, and one sharp band $\left(1739 \mathrm{~cm}^{-1}\right)$ characteristic of ester carbonyl group. $\mathrm{OH}$ band from 3000 to $3600 \mathrm{~cm}^{-1}$ was characteristic of dextran hydroxyls. After $10 \mathrm{~min}$ UV-irradiation (power $1150 \mathrm{~mW} / \mathrm{cm}^{2}$ ), FT-IR chart shows a total disappearance of above mentioned $\mathrm{NO}_{2}$ characteristic bands, while one new band characteristic of carboxylic acid groups appears at $1650 \mathrm{~cm}^{-1}$. In addition, a very broad band centered at $3440 \mathrm{~cm}^{-1}$, characteristic of OH from $\mathrm{CO}_{2} \mathrm{H}$ interfering with $\mathrm{OH}$ of dextran, was observed.

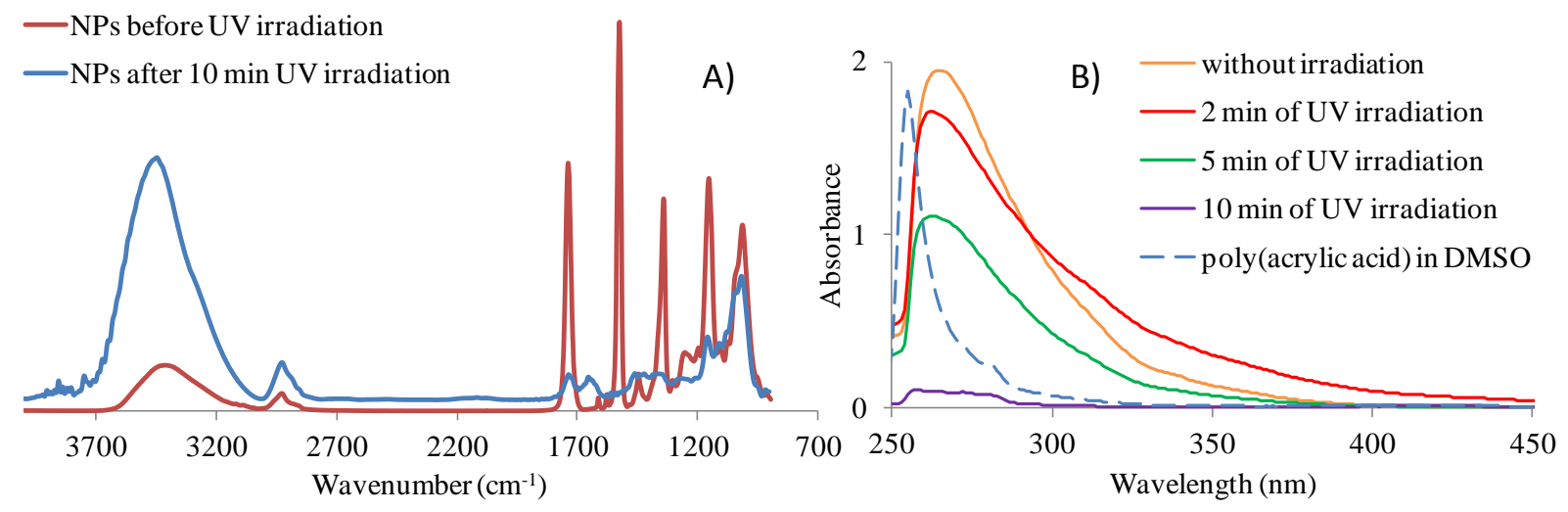

Figure 4. A) FT-IR charts of NPs before and after 10 min UV-irradiation. B) Evolution of UV spectra of NPs during UV-irradiation and of PAA in DMSO $(0.1 \mathrm{mg} / \mathrm{mL})$. NPs are based on Dex(15)-g-14PNBA 3,500 (Run 2, Table 1). Power irradiation was $1150 \mathrm{~mW} / \mathrm{cm}^{2}$.

UV spectra of NPs, irradiated or not, washed by DCM then dissolved in DMSO, are shown on Figure 4B. One peak at $275 \mathrm{~nm}$, corresponding to $o$-nitrobenzyl ester, was observed in the case of non-irradiated NPs and its intensity decreased with increasing the irradiation duration. No 
band at $325 \mathrm{~nm}$, characteristic of $o$-nitrosobenzaldehyde by-product, was observed according to the good DCM washing. After 10 min UV-irradiation, we still observed a small band over range 250-280 nm that may correspond to the electronic transitions as $\pi \rightarrow \pi^{*}$ and $n \rightarrow \pi^{*}$ of carboxylic acid groups (PAA grafts) and of the esters linking grafts onto dextran backbone.[54] Indeed, the UV spectrum of PAA $\left(\overline{M_{n}}=1,800 \mathrm{~g} / \mathrm{mol}\right)$ in DMSO shows one band over range of wavelengths

from 250 to $280 \mathrm{~nm}$ (Figure 4B).

\subsection{1) Effect of the medium}

We choose to irradiate NPs (made by nanoprecipitation of Dex(15)-g-12PNBA, ${ }_{9,800}$, run 3, Table 1) in two different media: distilled water and PBS.

Firstly in the case of NPs dispersed in $\mathrm{H}_{2} \mathrm{O}$, the evolution of Normalized Mean Count Rate $\left(\mathrm{MCR} / \mathrm{MCR}_{\mathrm{o}}\right.$ ) with the duration of irradiation (power $1150 \mathrm{~mW} / \mathrm{cm}^{2}$ ) was drawn on Figure $5 \mathrm{~A}$. The Mean Count Rate value (MCR) was measured initially $\left(\mathrm{MCR}_{\mathrm{o}}\right)$ and after each irradiation duration (30 sec intervals). As shown, normalized MCR decreased until $120 \mathrm{sec}$ irradiation, then increased according to the swelling of the NPs. Actually, according to our previous results, PNBA grafts were not totally converted into PAA ones after $60 \mathrm{sec}$ of irradiation under this UVlamp power.[38] Consequently, after $60 \mathrm{sec}$ of irradiation, grafts are based on NBA and acrylic acid monomer units (P(NBA-co-AA) grafts). At full photolysis, PNBA grafts were converted into PAA ones as shown on Figure S2. But, as PAA is insoluble in pure water, PAA grafts present onto the dextran backbone, and thus in the core of NPs, lead to swell NPs, scattering laser beam of DLS as native NPs do.

Secondly, we carried out the same experiments in PBS buffer. When running irradiation, we observed a continuous decrease of normalized MCR until $90 \mathrm{sec}$ irradiation due to the 


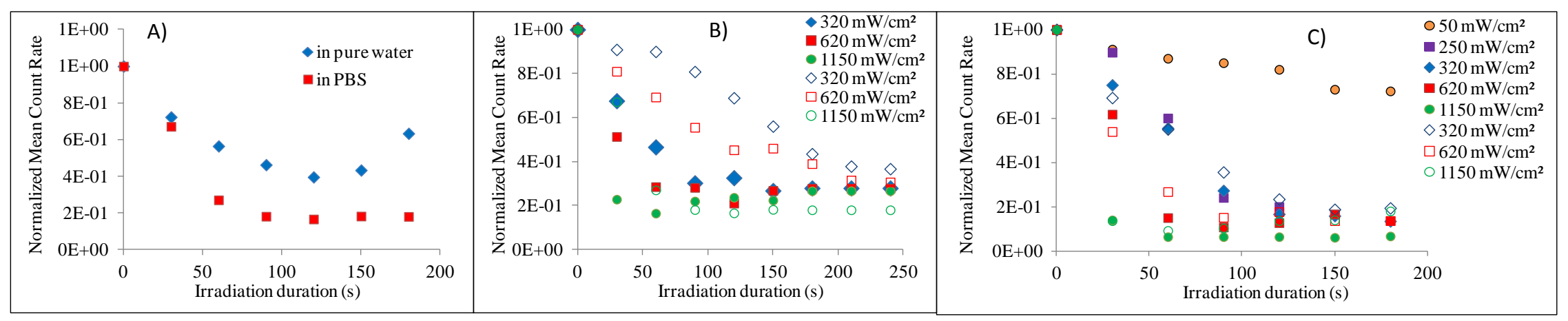

Figure 5. Normalized Mean Count Rate of NPs against duration of irradiation. A) Effect of the dispersion medium, irradiation power $1150 \mathrm{~mW} / \mathrm{cm}^{2}$ (run 3, Table 1). B) Effect of the irradiation power in PBS. Run 2, Table 1 (solid symbols) and run 3 , Table 1 (open symbols). C) Effect of the irradiation power in PBS. Run 6, Table 1 (solid symbols) and run 11, Table 1 (open symbols). 
progressive solubilisation of Dex-g-P(NBA-co-AA) glycopolymers in PBS, leading to the disappearance of NPs (Figure 5A). After $90 \mathrm{sec}$ irradiation, normalized MCR was constant to low value. At this time, all NPs were disappeared and converted to dissolved Dex-g-P(NBA-coAA) glycopolymers. Indeed, in such a buffer, PAA grafts were converted to their salts, that are readily soluble.

\subsection{2) Effects of the irradiation power and of the nanoparticles chemistry}

Firstly, NPs based on $\operatorname{Dex}(15)-\mathrm{g}-14 \mathrm{PNBA}_{3,500}\left(\mathrm{~F}_{\mathrm{PNBA}}=75 \%\right.$, run 2, Table 1) were irradiated under various powers (Figure 5B) in PBS. For one given irradiation power, normalized MCR decreased with increasing the irradiation duration until reaching a stable value. Secondly, NPs based on Dex(15)-g-12PNBA $9,800\left(\mathrm{~F}_{\mathrm{PNBA}}=85 \%\right.$, run 3, Table 1) show a slower decrease of MCR, that is explained by both the higher number of NBA monomer units in glycopolymer and the higher hydrophobicity of the NPs. Therefore, for one given irradiation power, higher duration of irradiation is necessary to obtain water-soluble Dex-g-P(NBA-co-AA) glycopolymers from run 3 compared to run 2 (Table 1). Increasing the irradiation power leads to disrupt a higher NPs number for the same irradiation time. Same observation was done for NPs made by emulsion/evaporation process (Figure 5C). Moreover, if we compare the decreasing of normalized MCR for NPs made with or without an in situ CuAAC (runs 6 and 11, Table 1), we can conclude that the presence of triazole rings does not prevent the NPs disruption as the kinetics appeared close. At higher irradiation duration, MCR of irradiated "clicked" NPs (run 11, Table 1) seems to be higher than that observed in case of NPs produced without CuAAC (run 6, Table 1). In fact, in the case of NPs produced without CuAAC, total photolysis will lead to a blend of dextran and PAA chains in comparison with Dex-g-PAA produced after quantitative photolysis of "clicked" NPs that may organize themselves in aqueous phase. 


\section{5) Light-sensitive nanoparticles cytotoxicity}

\subsection{1) Nanoparticles cytotoxicity}

In order to evaluate the biocompatibility of such PNBA-based NPs, their cytotoxicity was determined towards Caco-2 cells using MTT assay. In literature, diblock copolymers containing one PNBA part or some $o$-nitrobenzyl ester linkages were already proved to be not cytotoxic towards human breast cancer cells (MDA-MB-231)[55], (MDA-MB-435)[56] or human umbilical vein endothelial cells (HUVEC cells).[33] But to the best of our knowledge, studies dealing with the cytotocixity of $o$-nitrobenzyl-based copolymers or PNBA-based NPs towards Caco-2 have never been reported. The Caco-2 cells viability was measured after 24 h (Figure S5) and $48 \mathrm{~h}$ (Figure 6) incubation with various NPs batches formulated by either nanoprecipitation or emulsion/organic solvent evaporation with (or without) in situ $\mathrm{CuAAC}$, and using various NPs dispersion concentration (less than or equal to $227 \mu \mathrm{g} / \mathrm{mL}$ ). As shown in Figure 6, NPs until $113.5 \mu \mathrm{g} / \mathrm{mL}$ do not exhibit cell toxicity (cell viability $\sim 100 \%$ ) whatever the NPs formulation process or the use of an in situ CuAAC. At the NPs concentration corresponding to $227 \mu \mathrm{g} / \mathrm{mL}$, a very low decrease of the cell viability can also be observed for some NPs. Consequently, for experiments hereafter described, the NPs concentration equal to $113.5 \mu \mathrm{g} / \mathrm{mL}$ will be used as it has been considered that same results are observed whatever the NPs batch.

\subsection{2) Irradiation of Caco-2 cells}

The Caco-2 cells viability was investigated after cells exposure to UV-irradiation, by varying power and duration of irradiation. As shown in Figure 7, 100\% Caco-2 cell viability was observed after $24 \mathrm{~h}$ or $48 \mathrm{~h}$ incubation by applying $30 \mathrm{sec}$ irradiation with a power of 60 $\mathrm{mW} / \mathrm{cm}^{2}$. However, this viability decreased when increasing either the irradiation duration or the 


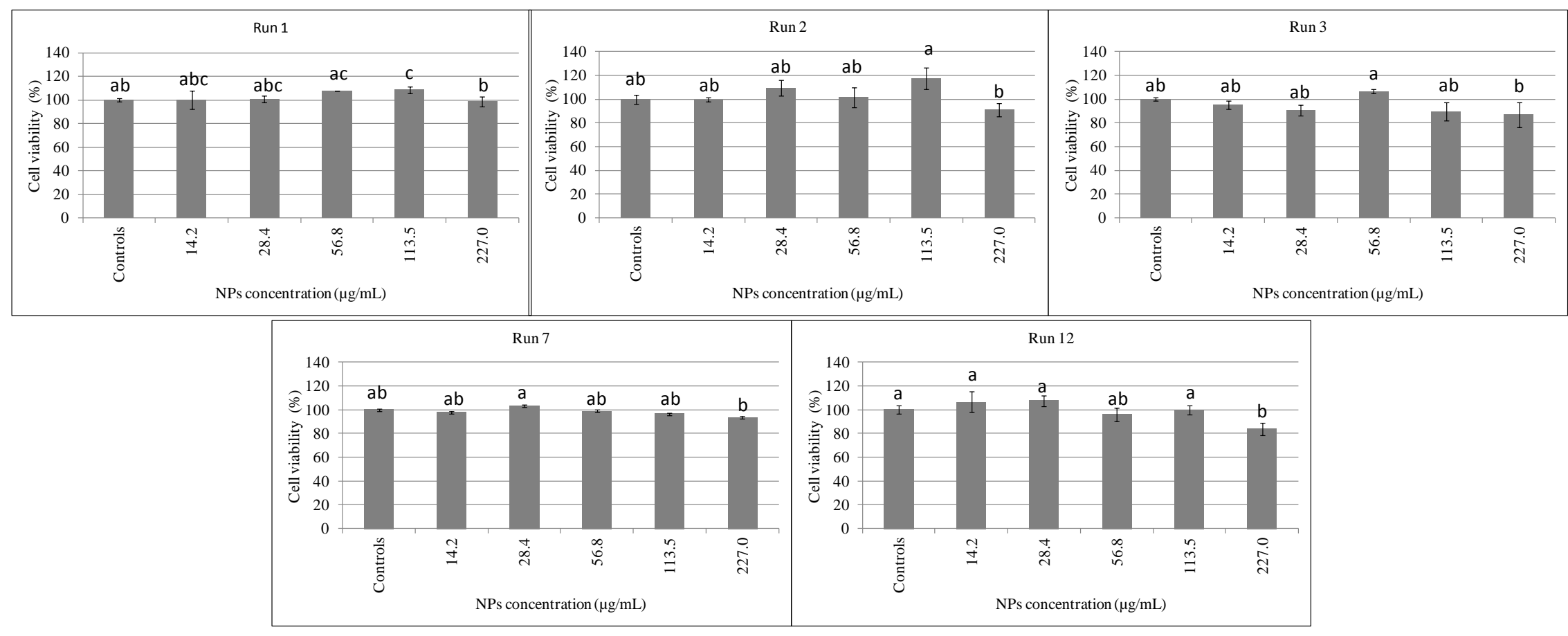

Figure 6. Cytotoxicity of NPs (see runs Table 1) towards Caco-2 cells after $48 \mathrm{~h}$ incubation. Values not followed by the same letter are significantly different at the $0.05 \%$ level (Duncan's test). 


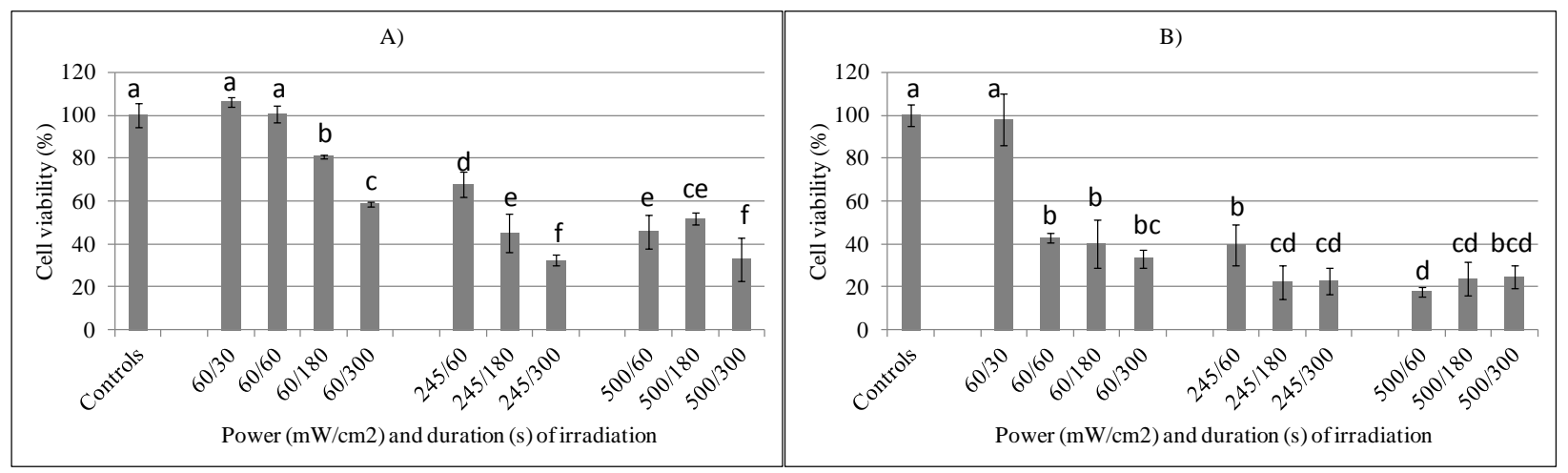

Figure 7. Effect of the irradiation power/duration on the Caco-2 cell viability after (A) $24 \mathrm{~h}$ and (B) $48 \mathrm{~h}$ incubation. Values not followed by the same letter are significantly different at the 0.05\% level (Duncan's test).

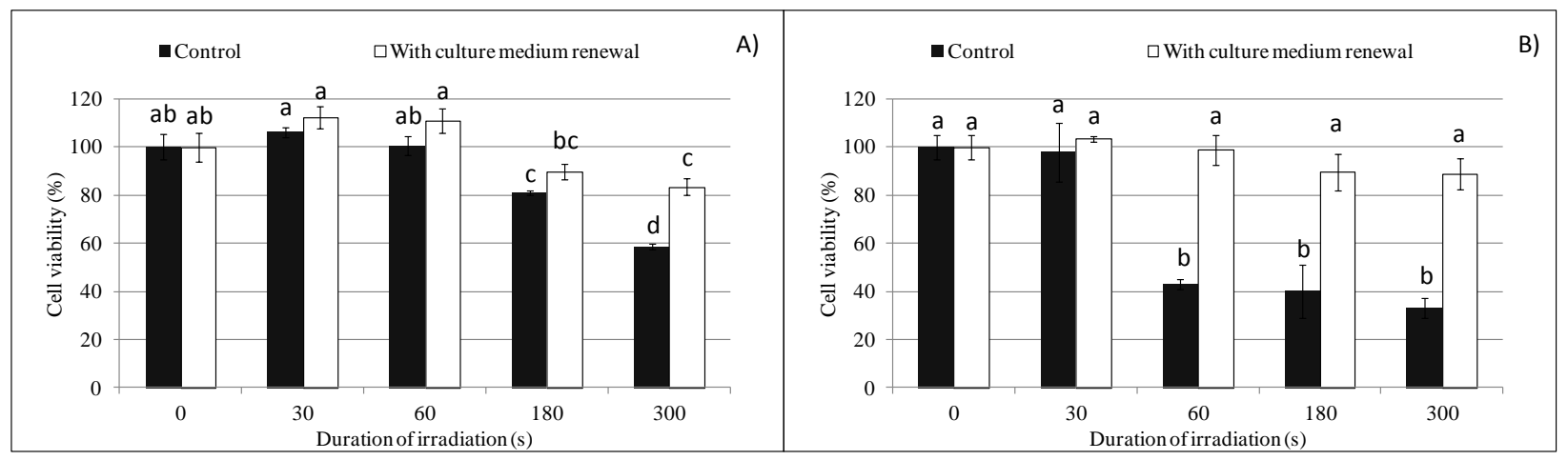

Figure 8. Effect of the culture medium renewal $4 \mathrm{~h}$ after the irradiation treatment (power: 60 $\mathrm{mW} / \mathrm{cm}^{2}$ ) on the Caco-2 cell viability. The viability was estimated after (A) $24 \mathrm{~h}$ and (B) $48 \mathrm{~h}$ incubation. Values not followed by the same letter are significantly different at the $0.05 \%$ level (Duncan's test).

irradiation power. In order to reduce the side-effects of the UV-irradiation treatment, the replacement of the culture medium was performed $4 \mathrm{~h}$ after the irradiation, then cells were incubated during an additional $24 \mathrm{~h}$ or $48 \mathrm{~h}$ before carrying the MTT assay. As shown in Figure 8 , this change has clear benefits on the cell viability as around $85-90 \%$ was still observed after 48 
$\mathrm{h}$ incubation (300 sec of irradiation at power $60 \mathrm{~mW} / \mathrm{cm}^{2}$ ) versus less than $40 \%$ without medium culture renewal.

\subsection{3) Irradiation of Caco-2 cells incubated with nanoparticles}

Finally, Caco-2 cells were exposed to $0.114 \mathrm{mg} / \mathrm{mL}$ of NPs (run 7, Table 1) and to irradiation (power $60 \mathrm{~mW} / \mathrm{cm}^{2}$ ). In some experiments and as previously done, the culture medium was renewed $4 \mathrm{~h}$ after the irradiation, then cells were incubated during $24 \mathrm{~h}$ or $48 \mathrm{~h}$ before carrying the MTT assay. With $30 \mathrm{sec}$ irradiation and when the culture medium was not replaced, cell viability reached $100 \%$ after $24 \mathrm{~h}$ incubation (Figure S6) but decreased up to $45 \%$ after $48 \mathrm{~h}$ incubation (Figure 9) in agreement with the possible cytotoxicity[55] of the $o$-nitrobenzaldehyde by-product produced during the photolysis of PNBA part (Figure S2). Nevertheless, with the same irradiation duration, a clear improvement of the cell viability can be observed when renewing the culture medium (Figure 9), which also mimics the dilution of the $o$ nitrobenzaldehyde by-product in fluid body. The cell viability still reached $100 \%$ after $60 \mathrm{sec}$ irradiation, but longer irradiation led to the decrease of the cell viability. For instance, up to $55 \%$ of cell viability was observed after 3 min irradiation.

\section{4) CONCLUSIONS}

PNBA core/Dex shell NPs were formulated by comparing two different processes: nanoprecipitation of amphiphilic Dex-g-PNBA glycopolymers or emulsion/organic solvent evaporation. Within this later process, we carried out (or not) an in situ CuAAC. Whatever the process used, NPs with average diameter from 120 to $140 \mathrm{~nm}$ were obtained, then characterized in terms of dextran amount per gram of PNBA (from 100 to around $300 \mathrm{mg}$ of dextran / $\mathrm{g}$ of 


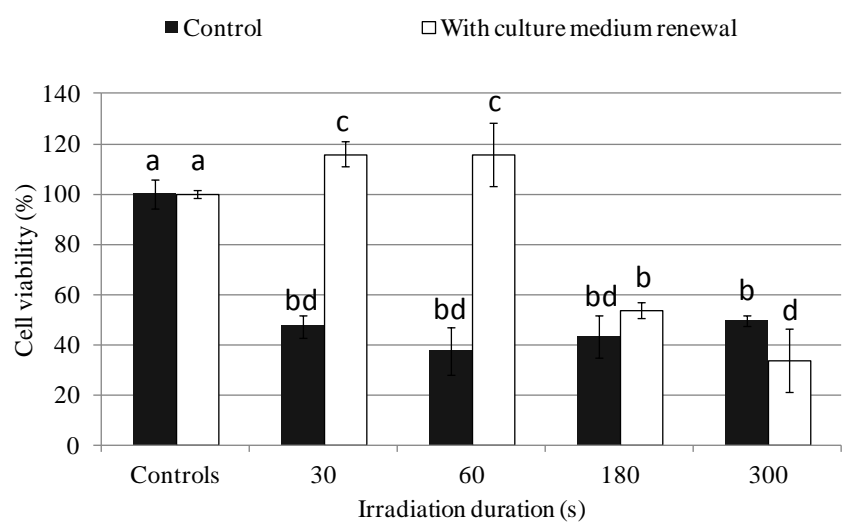

Figure 9. Caco-2 cell viability (after $48 \mathrm{~h}$ incubation) after exposure to NPs, then UV irradiation (power: $60 \mathrm{~mW} / \mathrm{cm}^{2}$ ) with various durations. The medium culture was renewed (or not) $4 \mathrm{~h}$ after the irradiation. Concentration of NPs (run 7, Table 1) was $0.114 \mathrm{mg} / \mathrm{mL}$. Values not followed by the same letter are significantly different at the $0.05 \%$ level (Duncan's test).

PNBA). From the zeta potential values, one dextran surface layer thickness of 3-5 nm was measured in the case of NPs made by nanoprecipitation, while an 8-10 nm thickness was estimated using emulsion/organic solvent evaporation, carrying or not in situ CuAAC. The colloidal stability of all NPs batches in the presence of salt was proved, but in the presence of SDS we observed $85 \%$ desorption of the dextran shell for NPs formulated by emulsion/organic solvent evaporation without CuAAC. Fortunately, less or equal up to $4 \%$ desorption was reached in the case of NPs made by emulsion/organic solvent evaporation with in situ CuAAC or nanoprecipitation processes, due to the triazole ring links between the dextran shell and the PNBA core.

Photosensitive property of such PNBA-based NPs was evaluated under UV light irradiation by firstly studying the photolysis kinetics, then varying either the suspension medium or the irradiation parameters. We observed that NPs disappeared in PBS medium and were converted to 
dissolved Dex-g-P(NBA-co-AA) glycopolymers before their total photolysis. Such photolysis may be controlled depending on the irradiation mode and the chemical composition of NPs. NPs disappearance kinetics depend also on the irradiation power: higher the power was, faster the NPs disruption was.

The biocompatibility of these photosensitive NPs towards Caco- 2 cells was proved by MTT assay, whatever the NPs formulation process and the in situ CuAAC occurrence. In parallel, the cell viability after UV-irradiation treatment was studied. It was shown that the replacement of the culture medium $4 \mathrm{~h}$ after the irradiation allows an irradiation treatment of the Caco-2 with power corresponding to $60 \mathrm{~mW} / \mathrm{cm}^{2}$ up to $300 \mathrm{sec}$ : after $48 \mathrm{~h}$ incubation, the cell viability remained at 85-90\%. Finally, after exposure to PNBA-based NPs then to UV-irradiation (power: 60

$\left.\mathrm{mW} / \mathrm{cm}^{2}\right), 100 \%$ cell viability was still observed after $60 \mathrm{sec}$ irradiation. These results open the way to future experiments dealing with such light-sensitive PNBA/Dex NPs. In the very next future, the loading of such NPs with anticancer drugs, then their release induced by UVirradiation will be investigated. Moreover, we will show that the $o$-nitrobenzaldehyde side-effect is negligible in comparison to the anticancer drug activity.

\section{ASSOCIATED CONTENT}

Supplementary data related to this article can be found in the online version of this article: Surface tension of alkynated dextran. Photolysis of Dex-g-PNBA. Characteristics and colloidal stability of NPs. Caco-2 cells viability after exposure to NPs, then (or not) to UV-irradiation treatment.

\section{ACKNOWLEDGMENT}


M. El Founi was supported by a grant of the French Ministry in charge of Research. S.M.A. Soliman gratefully acknowledges support from an Erasmus Mundus External Cooperation Windows - Flowby Flow EU-Egypt Bridge Building (FFEEBB) Graduate Research Fellowship. The authors express their highest gratitude to Marie-Christine Grassiot (LCPM) and Caroline Sejil (LCPM) for SEC measurements, to Olivier Fabre (LCPM) for NMR measurements and to Bruno Ebel (LRGP) for statistical analyses.

\section{REFERENCES}

[1] J.H. Park, S. Lee, J.H. Kim, K. Park, K. Kim, I.C. Kwon, Polymeric nanomedicine for cancer therapy, Prog. Polym. Sci. 33 (2008) 113-137

[2] T. Lammers, S. Aime, W.E. Hennink, G. Storm, F. Kiessling, Theranostic nanomedicine, Account Chem. Res. 44 (2011) 1029-1038

[3] S. Moein Moghimi, A. Christy Hunter, J. Clifford Murray, Nanomedicine: current status and future prospects, FASEB J. 19 (2005) 311-330

[4] Y. Liu, H. Miyoshi, M. Nakamura, Nanomedicine for drug delivery and imaging: A promising avenue for cancer therapy and diagnosis using targeted functional nanoparticles, Int. J. Cancer 120 (2007) 2527-2537

[5] R.K. Jain, T. Stylianopoulos. Delivering nanomedicine to solid tumors, Nat. Rev. Clin. Oncol. 7 (2010) 653-664

[6] A. Vonarbourg, C. Passirani, P. Saulnier, J.P. Benoit. Parameters influencing the stealthiness of colloidal drug delivery systems. Biomaterials 27 (2006) 4356-4373

[7] M. D. Howard, M. Jay, T. D. Dziubla, X. Lu. PEGylation of nanocarrier drug delivery systems: State of the art, J. Biomed. Nanotechnol. 4 (2008) 133-148

[8] E. M. Pelegri-O'Day, E. W. Lin, H. D. Maynard, J. Am. Chem. Soc. 136 (2014) 1432314332 
[9] K. Knop, R. Hoogenboom, D. Fischer, U. S. Schubert, Poly(ethylene glycol) in drug delivery: pros and cons as well as potential alternatives, Angew. Chem. Int. Ed. 49 (2010) 6288-6308

[10] Z. H. Liu, Y. P. Jiao, Y. F. Wang, C. R. Zhou, Z. Y. Zhang, Polysaccharides-based nanoparticles as drug delivery systems, Adv. Drug Deliv. Rev. 60 (2008) 1650-1662

[11] C. Gavory, A. Durand, J.-L. Six, C. Nouvel, E. Marie, M. Léonard, Polysaccharidecovered nanoparticles prepared by nanoprecipitation, Carbohyd. Polym. 84 (2011) 133-140

[12] M. Laville, J. Babin, I. Londono, M. Legros, C. Nouvel, A. Durand, R. Vanderesse, M. Leonard, J.-L. Six, Polysaccharide-covered nanoparticles with improved shell stability using synthetic strategies based on click-chemistry, Carbohyd. Polym. 93 (2013) 537-546

[13] C. Nouvel, J. Raynaud, E. Marie, E. Dellacherie, J.-L. Six, A. Durand, Biodegradable nanoparticles made from polylactide-grafted dextrancopolymers, J. Colloid Interface Sci. 330 (2009) 337-343

[14] A. Kumari, S.K. Yadav, S.C Yada, Biodegradable polymeric nanoparticles based drug delivery systems, Colloid Surf. B-Biointerfaces 75 (2010) 1-18

[15] E. Locatelli, M. Comes Franchini, Biodegradable PLGA-b-PEG polymeric nanoparticles: synthesis, properties, and nanomedical applications as drug delivery system, J. Nanopart. Res. 14 (2012) 1316-1332

[16] D. B. Pacardo, F.S. Ligler, Z. Gu, Programmable nanomedicine: synergistic and sequential drug delivery systems, Nanoscale 7 (2015) 3381-3391

[17] D. Mishra, J. R. Hubenak, A. B. Mathur, Nanoparticle systems as tools to improve drug delivery and therapeutic efficacy, J. Biomed. Mater. Res. Part A 101A (2013) 3646-3660.

[18] S. Bamrungsap, Z. Zhao, T. Chen, L. Wang, C. Li, T. Fu, W. Tan, Nanotechnology in therapeutics: a focus on nanoparticles as a drug delivery system, Nanomedicine, 7 (2012) 1253-1271 
[19] T.M. Allen, P.R. Cullis, Drug delivery systems: entering the mainstream, Science 303 (2004) 1818-1822

[20] B. Taghizadeh, S. Taranejoo, S. A. Monemian, Z. S. Moghaddam, K. Daliri, H. Derakhshankhah, Z. Derakhshani, Classification of stimuli-responsive polymers as anticancer drug delivery systems, Drug Deliv. 22 (2015) 145-155

[21] C. Alvarez-Lorenzo, A. Concheiro, Intelligent drug delivery systems: polymeric micelles and hydrogels, Mini-Rev. Med. Chem. 8 (2008) 1065-1074

[22] M. Karimi, A. Ghasemi, P. Sahandi Zangabad, R. Rahighi, S. M. Moosavi Basri, H. Mirshekari, M. Amiri, Z. Shafaei Pishabad, A. Aslani, M. Bozorgomid, D. Ghosh, A. Beyzavi, A. Vaseghi, A. R. Aref, L. Haghani, S. Bahramia, M. R. Hamblin, Smart micro/nanoparticles in stimulus-responsive drug/gene delivery systems, Chem. Soc. Rev. 45 (2016) $1457-1501$

[23] D. Liu, F. Yang, F. Xiong, N. Gu, The smart drug delivery system and its clinical potential, Theranostics 6 (2016) 1306-1323

[24] N. Rapoport. Physical stimuli-responsive polymeric micelles for anti-cancer drug delivery, Prog. Polym. Sci. 32 (2007) 962-990

[25] S. Dai, P. Ravi, K.C. Tam, Thermo- and photo-responsive polymeric systems, Soft Matter 5 (2009) 2513-2533

[26] F. D. Jochum, P. Theato, Temperature- and light-responsive smart polymer materials, Chem. Soc. Rev. 42 (2013) 7468-7483

[27] Q. Yan, D. Han, Y. Zhao, Main-chain photoresponsive polymers with controlled location of light-cleavable units: from synthetic strategies to structural engineering, Polym. Chem. 4 (2013) 5026-5037

[28] G. Liu, W. Liu, C.-M. Dong, UV- and NIR-responsive polymeric nanomedicines for ondemand drug delivery, Polym. Chem. 4 (2013) 3431-3443 
[29] O. Bertrand, J.-F. Gohy, Photo-responsive polymers: synthesis and applications, Polym. Chem. 8 (2017) 52-73

[30] V. Marturano, P. Cerruti, M. Giamberini, B. Tylkowski, V. Ambrogi, Light-responsive polymer micro- and nano-capsules, Polymers 9 (2017) 8

[31] H. Zhao, E. S. Sterner, E. B. Coughlin, P. Theato, o-Nitrobenzyl alcohol derivatives: Opportunities in polymer and materials science, Macromolecules 45 (2012) 1723-1736

[32] J. Jiang, X. Tong, D. Morris, Y. Zhao, Toward photocontrolled release using lightdissociable block copolymer micelles, Macromolecules 39 (2006) 4633-4640

[33] Q. Jin, T. Cai, H. Han, H. Wang, Y. Wang, J. Ji, Light and pH dual-degradable triblock copolymer micelles for controlled intracellular drug release, Macromol. Rapid Commun. 35 (2014) 1372-1378

[34] G. Jiang, T. Jiang, H. Chen, L. Li, Y. Liu, H. Zhou, Y. Feng, J. Zhou, Preparation of multi-responsive micelles for controlled release of insulin, Colloid Polym. Sci. 293 (2015) 209-215

[35] S. Jana, A. Bose, A. Saha, T. K. Mandal, Photocleavable and tunable thermoresponsive amphiphilic random copolymer: self-assembly into micelles, dye encapsulation, and triggered release, J. Polym. Sci., Part A: Polym. Chem. 55 (2017) 1714-1729

[36] X. Jiang, C. A. Lavender, J. W. Woodcock, B. Zhao, Multiple micellization and dissociation transitions of thermo- and light-sensitive poly(ethylene oxide)-bpoly(ethoxytri(ethylene glycol) acrylate-co-o-nitrobenzyl acrylate) in water, Macromolecules 41 (2008) 2632-2643

[37] S. M. A. Soliman, C. Nouvel, J. Babin, J.-L. Six, o-Nitrobenzyl acrylate is polymerizable by Single Electron Transfer-Living Radical Polymerization, J. Polym. Sci., Polym. Chem. 52 (2014) 2192-2201

[38] S. M. A. Soliman, L. Colombeau, C. Nouvel, J. Babin, J.-L. Six, Amphiphilic photoresponsive dextran-g-poly(o-nitrobenzyl acrylate) glycopolymers, Carbohyd. Polym. 136 (2016) 598-608 
[39] S. Jana, A. Saha, T. K. Paira, T. K. Mandal, Synthesis and self-aggregation of poly(2ethyl-2-oxazoline)-based photocleavable block copolymer: micelle, compound micelle, reverse micelle, and dye encapsulation/release, J. Phys. Chem. B 120 (2016) 813-824

[40] Z. Xu, B. Yan, J. Riordon, Y. Zhao, D. Sinton, M. G. Moffitt, Microfluidic synthesis of photoresponsive spool-like block copolymer nanoparticles: flow-directed formation and light triggered dissociation, Chem. Mater. 27 (2015) 8094-8104

[41] D. Royston, D. G. Jackson, Mechanisms of lymphatic metastasis in human colorectal adenocarcinoma, J. Pathol. 217 (2009) 608-619

[42] L. Baandrup, L. T. Thomsen, T. B. Olesen, K. K. Andersen, B. Norrild, S. K. Kjaer, The prevalence of human papillomavirus in colorectal adenomas and adenocarcinomas: A systematic review and meta-analysis, Eur. J. Cancer 50 (2014) 1446-1461

[43] J. J. Smith, N. G. Deane, P. Dhawan, R. D. Beauchamp, Regulation of metastasis in colorectal adenocarcinoma: A collision between development and tumor biology, Surgery 144 (2008) 353-366

[44] S.R. Deshiikan, K.D. Papadopoulos, Modified Booth equation for the calculation of zeta potential, Colloid. Polym. Sci. 276 (1998) 117-124

[45] K. Poltorak, A. Durand, M. Leonard, J.-L. Six, C. Nouvel, Interfacial click chemistry for improving both dextran shell density and stability of biocompatible nanocapsules, Colloid Surface A 483 (2015) 8-17

[46] W.G. Eversole, W.W. Boardman, The effect of electrostatic forces on electrokinetic potentials, J. Chem. Phys. 9 (1941) 798-801

[47] T. Mosman, Rapid calorimetric assay for cellular growth and survival: Application to proliferation and cytotoxicity assays, J. Immunol. Methods 65 (1983) 55-63

[48] D. Chognot, M. Leonard, J.-L. Six, E. Dellacherie, Surfactive water-soluble copolymers for the preparation of controlled surface nanoparticles by double emulsion/solvent evaporation, Colloid Surface B, 51 (2006) 86-92 
[49] P. Cintas, G. Palmisano, G. Cravotto, Power ultrasound in metal-assisted synthesis: From classical Barbier-like reactions to click chemistry, Ultrason. Sonochem. 18(S1) (2011) 836841

[50] M. T. Peracchia, C. Vauthier, D. Desmaele, A. Gulik, J.-C. Dedieu, M. Demoy, J. d'Angelo, P. Couvreur, Pegylated nanoparticles from a novel methoxypolyethylene glycol cyanoacrylate-hexadecyl cyanoacrylate amphiphilic copolymer, Pharm. Res. 15 (1998) 550556

B. Cattoz, T. Cosgrove, M. Crossman, S.W. Prescott, Surfactant-mediated desorption of polymer from the nanoparticle interface, Langmuir 28 (2012) 2485-2492

[52] A.M. Blokhus, K. Djurhuus, Adsorption of poly(styrene sulfonate) of different molecular weights on alpha-alumina: effect of added sodium dodecyl sulfate, J. Colloid Interface Sci. 296 (2006) 64-70

[53] R. A. Lauten, A.-L. Kjøniksen, B. Nystrom, Adsorption and desorption of unmodified and hydrophobically modified ethyl(hydroxyethyl)cellulose on polystyrene latex particles in the presence of ionic surfactants using dynamic light scattering, Langmuir 16 (2000) 44784484

[54] S. Kavlak, H. K. Can, A. Guner, Interaction of poly(maleic anhydride-alt-acrylic acid) with transition metal cations, $\mathrm{Ni}_{2}, \mathrm{Cu}_{2}$, and $\mathrm{Cd}_{2}$ : a study by $\mathrm{UV}-\mathrm{Vis}$ spectroscopy and viscosimetry, J. Appl. Polym. Sci. 92 (2004) 2698-2705

[55] P. Anilkumar, E. Gravel, I. Theodorou, K. Gombert, B. Thézé, F. Ducongé, E. Doris, Nanometric micelles with photo-triggered cytotoxicity, Adv. Funct. Mater. 24 (2014) 52465252

[56] J. Song, Z. Fang, C. Wang, J. Zhou, B. Duan, L. Pu, H. Duan, Photolabile plasmonic vesicles assembled from amphiphilic gold nanoparticles for remote-controlled traceable drug delivery, Nanoscale 5 (2013) 5816-5824 